\title{
Influence of surface functionalities on ethanol adsorption characteristics in activated carbons for adsorption heat pumps
}

Hyun-Sig Kila ${ }^{\mathrm{a}}$, Taegon Kim ${ }^{\mathrm{a}, \mathrm{b}}$, Koichiro Hata ${ }^{\mathrm{a}}$, Keiko $\operatorname{Ideta}^{\mathrm{c}}$, Tomonori Ohba ${ }^{\mathrm{d}}$, Hirofumi Kanoh ${ }^{\mathrm{d}}$, Isao Mochida ${ }^{\mathrm{b}}$, Seong-Ho Yoon ${ }^{\mathrm{a,c}}$, and Jin Miyawaki ${ }^{\mathrm{c}, *}$

${ }^{a}$ Interdisciplinary Graduate School of Engineering Sciences, Kyushu University, 6-1 Kasuga-koen, Kasuga, Fukuoka 816-8580, JAPAN.

${ }^{b}$ Research and Education Center of Carbon Resources, Kyushu University, 6-1 Kasuga-koen, Kasuga, Fukuoka 816-8580, JAPAN.

${ }^{c}$ Institute for Materials Chemistry and Engineering, Kyushu University, 6-1 Kasuga-koen, Kasuga, Fukuoka 816-8580, JAPAN.

${ }^{d}$ Graduate School of Science, Chiba University, 1-33 Yayoi, Inage, Chiba 263-8522, JAPAN.

*Corresponding author:

Jin Miyawaki,

Tel: +81-(0)92-583-8857

Fax: +81-(0)92-583-7897

Email: miyawaki@cm.kyushu-u.ac.jp

Postal address: Institute for Materials Chemistry and Engineering, Kyushu University, 6-1 Kasugakoen, Kasuga, Fukuoka 816-8580, Japan. 


\begin{abstract}
To develop high-performance activated carbons (ACs) for adsorption heat pumps (AHPs), it is important to characterize the adsorption behaviors of the refrigerant molecules in the pores of ACs. Not only pore structures, such as pore size and shape, but also surface functionalities strongly influences the adsorption behaviors, especially for polar molecules, such as water and ethanol, which are typical refrigerants for AHP. In this study, we examined the influence of surface functional groups on the adsorption behaviors of ethanol molecules in carbon micropores using model ACs with different amounts of oxygen-containing surface functional groups but comparable porosities. For the AC with an increased amount of surface functional groups, ethanol adsorption/desorption isotherms showed significant decreases in the adsorption amounts and shortened adsorption equilibrium times compared to those with less surface functional groups throughout the entire relative pressure region. This suggests diffusional hindrance of ethanol molecules in micropores with abundant surface functional groups. To verify our hypothesis, we examined the influence of surface functional groups on the adsorption behavior of ethanol molecules using a solid-state NMR technique. The NMR results revealed that the hydroxyl group of ethanol molecules strongly interacts with the surface functional groups, giving rise to an oriented adsorption of ethanol molecules in the micropores with oxygen-containing surface functional groups. Furthermore, electrochemical analyses confirmed that diffusion resistance of electrolyte ions in the micropores increases after the introduction of oxygen-containing surface functional groups, which supports our hypothesis.
\end{abstract}

Keywords: Activated carbon; adsorption heat pump; oxygen-containing functional group; solid-state NMR; electrochemical analysis; diffusional hindrance 


\section{Introduction}

Heat pumps are an environmentally friendly system that provides heating and cooling effects using relatively low-level heat sources such as solar energy, geothermal heat, and industrial waste heat $[1,2]$. Recently, adsorption heat pumps (AHPs) have been actively studied and developed because they can effectively use low-temperature waste heat at around $373 \mathrm{~K}$ or lower. Two approaches have been used to improve the performance of AHP systems: chemical engineering-based and material-based approaches. For the latter approach, various adsorbent-adsorbate pairs, such as silica gel-water [3, 4], zeolite-water [5], activated carbon (AC)- $\mathrm{CO}_{2}$ [6], $\mathrm{AC}-$ water [7], AC-methanol [8, 9], and AC-ethanol $[1,9]$ pairs, have been considered because adsorptive and thermal characteristics depend not only on individual properties of the adsorbent and adsorbate, but also on their combination. Demir et al. [10] discussed problems and solutions associated with AHP systems. For example, the zeolite-water pair showed low adsorbability of approximately $30 \mathrm{wt} . \%$ of the adsorbent. On the other hand, the ACethanol pair showed much higher adsorption properties of more than $150 \mathrm{wt} . \%$ of the adsorbent [11]. Attan et al. [12] also reported that AC fiber, which has a high specific surface area, high total pore volume, and narrow average pore size, showed good adsorptivity for numerous refrigerants, including water, ammonia, acetone, methanol, and ethanol. However, the adsorption behavior is influenced not only by pore structures, but also by surface functionalities, especially for polar molecules such as water and ethanol. In this study, we explored the role of surface functionalities of ACs on the adsorption behavior of ethanol molecules in carbon micropores.

To examine the influence of surface functionalities, model AC samples with comparable pore structures but different quantities of surface functionalities were required. Therefore, we controlled the oxygen contents using heat treatments in $\mathrm{H}_{2}$ or with $\mathrm{KOH}$ while maintaining the pore structure using an ultrahigh-surface-area AC, Maxsorb III [13], as the parent material. The model AC samples were used to investigate the influence of surface functionalities on adsorption performance, such as adsorption amounts and kinetics, as well as the adsorption states of the ethanol molecules in carbon micropores using solid-state nuclear magnetic resonance (NMR). NMR spectroscopy is based on physical phenomena of nuclei in a magnetic field absorbing and re-emitting electromagnetic radiation; NMR can provide detailed information regarding the structure, dynamics, and chemical state of molecules and is a powerful method for analyzing adsorption states of molecules and ions [14]. Moreover, electrochemical techniques, i.e., cyclic voltammetry and electrochemical impedance spectroscopy, 
were applied to obtain diffusional information on the materials (electrolyte ions) in carbon micropores with different amounts of oxygen-containing surface functional groups. Based on these results, we examined the influence of surface functionalities on the adsorption behaviors of molecules in the carbon micropores.

\section{Experimental}

Three AC samples were used in this study: Maxsorb III from Kansai Coke and Chemicals Co., Ltd. (designated as MAX in this study), $\mathrm{H}_{2}$-treated Maxsorb III (with a lower content of oxygen-containing functional groups, named $\mathrm{H}-\mathrm{MAX}$ ), and $\mathrm{KOH}$-activated $\mathrm{H}_{2}$-treated Maxsorb III (with higher contents of oxygen-containing functional groups, abbreviated as Ox-MAX). H-MAX was prepared using heat treatment of MAX under a reducing atmosphere $\left(\mathrm{Ar} / \mathrm{H}_{2}=8 / 2(\mathrm{v} / \mathrm{v})\right.$, total flow rate $\left.=250 \mathrm{~cm}^{3} / \mathrm{min}\right)$ at $600^{\circ} \mathrm{C}$ for $24 \mathrm{~h}$. To prepare Ox-MAX, $\mathrm{KOH}$ treatment was applied to $\mathrm{H}-\mathrm{MAX}$ at a $\mathrm{KOH} / \mathrm{carbon}$ weight ratio of 2. The mixture was heat-treated at $600^{\circ} \mathrm{C}$ for $1 \mathrm{~h}$ under $\mathrm{N}_{2}$ flow $\left(100 \mathrm{~cm}^{3} / \mathrm{min}\right)$. After the reaction, the remaining $\mathrm{KOH}$ and salts that formed during the heat treatment were removed by washing with $\mathrm{HCl}$ solution three times and deionized water once to adjust the $\mathrm{pH}$ to approximately 7. After washing, the collected samples were dried at $100^{\circ} \mathrm{C}$ for $3 \mathrm{~h}$ in an air oven and dried again at $150^{\circ} \mathrm{C}$ for $3 \mathrm{~h}$ in a vacuum oven.

Elemental compositions of AC samples were analyzed using a CHN analyzer (MT-5, Yanako, Japan). The assay of $\mathrm{O}$ content $\left(\mathrm{O}_{\text {diff. }}\right)$ was defined by subtracting the sum of the contents of $\mathrm{C}$, $\mathrm{H}$, and $\mathrm{N}$ from $100 \% . \mathrm{N}_{2}$ adsorption/desorption isotherms at $77 \mathrm{~K}$ were measured using volumetric adsorption equipment (Belsorp-Max-S, BEL Japan Inc., Japan) to investigate porosity. Ethanol adsorption/desorption kinetics and isotherms were gravimetrically measured at $303 \mathrm{~K}$. Fig. 1 shows the schematic diagram of a gravimetric adsorption apparatus. A sample was placed in a sample basket and into an adsorption chamber. Prior to adsorption measurements, the sample was pretreated at $150^{\circ} \mathrm{C}$ under vacuum for $2 \mathrm{~h}$. After cooling the sample, isothermal water and air baths were set to maintain the sample temperature at a constant $303 \mathrm{~K}$. By opening valves, ethanol vapor was introduced into the adsorption chamber from a liquid ethanol vessel. After closing the valves, the weight change of the sample was recorded until it reached adsorption equilibrium. Here, equilibrium was considered to be achieved when the weight remained constant for $15 \mathrm{~min}$. For the following measuring steps, the same valve operations were repeated and adsorption isotherms were obtained. 
In solid-state NMR studies, two types of isotope-labeled ethanol $\left(\mathrm{CD}_{3} \mathrm{CH}_{2} \mathrm{OH}\right.$ and $\left.\mathrm{CH}_{3} \mathrm{CH}_{2} \mathrm{OD}\right)$ were used to assess adsorption states of ethanol molecules in carbon micropores. The AC sample was pretreated at $150^{\circ} \mathrm{C}$ under $\mathrm{N}_{2}$ flow for $2 \mathrm{~h}$ for degassing. After exposure to saturated $\mathrm{CD}_{3} \mathrm{CH}_{2} \mathrm{OH}(\mathrm{CDN}$ Isotopes, 99.3 atom.\% D) or $\mathrm{CH}_{3} \mathrm{CH}_{2} \mathrm{OD}$ (CDN Isotopes, 99.8 atom.\% D) vapor in a $\mathrm{N}_{2}$-filled grove box for $72 \mathrm{~h}$ at room temperature, the sample was placed in a 3.2-mm NMR sample cell with sealing caps and then prepared for NMR measurements. ${ }^{2} \mathrm{H}$ single-pulse solid-state NMR spectra were acquired at a 5-kHz magic angle spinning (MAS) speed at room temperature using an 800-MHz solidstate NMR (JNM-ECA-800, JEOL, Japan) with a cross polarization/MAS probe.

Diffusional behaviors of electrolyte ions in micropores of the Maxsorb III series were studied using cyclic voltammetry and electrochemical impedance spectrometry using the conventional threeelectrode system (HZ-3000 automatic polarization system, Hokuto Denko, Japan). The working electrode was a dried thin film composed of a mixture of one of the Maxsorb III series and 15 wt.\% polyvinylidene fluoride (SOLEF of Solvay Chemicals, Belgium) in N-methyl-2-pyrrolidone (Wako Pure Chemical Industries, Ltd., Japan). Pt and $\mathrm{Ag} / \mathrm{AgCl}\left(\left[\mathrm{Cl}^{-}\right]=1 \mathrm{M}\right)$ were used as counter and reference electrodes. All potentials were reported against the reference electrode. $\mathrm{N}_{2}$ gas was used to remove oxygen species in a $0.5 \mathrm{M} \mathrm{H}_{2} \mathrm{SO}_{4}$ (Wako Pure Chemical Industries, Ltd., Japan) electrolyte solution. Cyclic voltammetry was performed to investigate the capacitances depending on potential sweep rates, which control the kinetic rate of electron exchange between the charged working electrode and electrolyte molecules. In addition, impedance measurements were performed to examine resistive properties between the working electrode and electrolytic diffusion by applying a low-amplitude alternating voltage of $5 \mathrm{mV}$ within the frequency range of $10 \mathrm{kHz}$ to $100 \mathrm{MHz}$ at an open circuit potential. In particular, diffusion behaviors of electrolyte molecules in carbon micropores with different amounts of surface functional groups were examined in this study.

\section{Results and Discussion}

Fig. 2 compares the $\mathrm{N}_{2}$ adsorption and desorption isotherms at $77 \mathrm{~K}$ for MAX, H-MAX, and OxMAX. A steep increase in the nitrogen adsorption amount at very low relative pressure, which is a characteristic feature of microporous materials, was observed for all samples. The $\mathrm{N}_{2}$ adsorption and desorption isotherms showed negligible hysteresis, indicative of an absence of mesopores. Table 1 contains the pore structural parameters estimated using the subtracting pore-effect method with the $\alpha_{S}$ plots of the $\mathrm{N}_{2}$ adsorption isotherms at $77 \mathrm{~K}$ [15] and the elemental compositions obtained from the 
CHN analysis of the prepared model samples. Specific surface areas, micropore volumes, and average pore widths of the three samples were comparable, indicating that they had similar pore structures. On the other hand, oxygen contents differed among the samples. Compared with $\operatorname{MAX}\left(\mathrm{O}_{\text {diff. }}=4.35 \%\right)$, the oxygen content of H-MAX was reduced to $1.75 \%$ by heat treatment under a reducing atmosphere, but Ox-MAX showed a much higher oxygen content of $10.46 \%$. Thus, these three samples were considered suitable for analyzing the influence of surface functionalities on the adsorption behavior of ethanol molecules in the carbon micropores.

Ethanol adsorption/desorption kinetics and isotherms were gravimetrically measured at $303 \mathrm{~K}$. The ethanol adsorption measurements were performed twice to confirm repeatability. Fig. 3 shows ethanol adsorption/desorption isotherms and adsorption/desorption equilibrium times at different relative pressures $\left(P / P_{0}\right)$ at $303 \mathrm{~K}$. The $\mathrm{H}_{2}$ treatment of MAX did not have a significant impact on the adsorption amounts and adsorption equilibrium times of ethanol. For Ox-MAX with an increased amount of oxygen-containing surface functionalities, significant decreases in the adsorption amounts of ethanol were observed (about 15\% compared with MAX and H-MAX). Furthermore, the adsorption equilibrium times were shortened to within $40 \mathrm{~min}$, which was significantly shorter than those of MAX and $\mathrm{H}-\mathrm{MAX}$, for the whole $P / P_{0}$ region. These results suggest diffusional hindrance of ethanol molecules in micropores with abundant surface functionalities. That is, polar ethanol molecules were thought to rapidly and strongly adsorb on the surface functionalities located near the pore entrance, and such "trapped" ethanol molecules inhibited further adsorption at deeper pore spaces.

Figs. 4 and 5 show ${ }^{2} \mathrm{H}$-NMR spectra of $\mathrm{CD}_{3} \mathrm{CH}_{2} \mathrm{OH}$-asdorbed and $\mathrm{CH}_{3} \mathrm{CH}_{2} \mathrm{OD}$-asdorbed Maxsorb III series at a 5-kHz MAS speed, respectively. Regardless of the different oxygen contents, the shape of the NMR spectra of the $\mathrm{CD}_{3} \mathrm{CH}_{2} \mathrm{OH}$-adsorbed samples were similar, although chemical shifts of the peak differed due to the deshielding effect of the oxygen-containing surface functional groups (Fig. 4) [16]. However, the $\mathrm{CH}_{3} \mathrm{CH}_{2} \mathrm{OD}$-adsorbed samples showed different NMR spectra (Fig. 5). The ACs with higher oxygen contents yielded broader spectra, i.e., shorter spin-spin relaxation times, $T_{2}$, which represents the lifetime of the signal in the transverse plane (XY plane); the line width of an NMR signal depends on $T_{2}$ (line width at half height $=1 / T_{2}$ ). Smaller $T_{2}$ value indicates slower motion of the observed atomic nucleus. Therefore, the observed $T_{2}$ suggests that hydroxyl groups of ethanol molecules interacted with the surface functionalities via hydrogen bonds. Furthermore, peaks of spinning side bands were clearly observed for the $\mathrm{CH}_{3} \mathrm{CH}_{2} \mathrm{OD}$-adsorbed samples (Fig. 5 (b)), suggesting that the $\mathrm{D}$ atoms of the adsorbed $\mathrm{CH}_{3} \mathrm{CH}_{2} \mathrm{OD}$ molecules were at relatively fixed states, at 
least during the time scale of the NMR measurements. Such peak broadening and appearance of spinning side band peaks were remarkable for Ox-MAX, with the highest oxygen content among the three samples used in this study. The NMR results were confirmed based on triplicate measurements. Taken together, these data indicate that ethanol molecules in micropores of ACs strongly interact with the surface functionalities and are in oriented adsorption states with the hydroxyl group facing the oxygen-containing surface functional groups.

Based on these results, it may be possible to study the influence of surface functionalities on the kinetics of molecules in the carbon micropores of the MAX series by using electrochemical analysis to determine the diffusional rates of electrolyte ions on working electrodes $[17,18]$. Fig. 6 shows cyclic voltammograms (CVs) for the Maxsorb III series in $0.5 \mathrm{M} \mathrm{H}_{2} \mathrm{SO}_{4}$. In Fig. 6 (a), the capacitive current (non-faradaic current) of MAX showed the typical rectangular shape with a very small amount of pseudo-capacitive current (faradaic current) induced by a redox reaction of the oxygen-containing surface functional groups with electrolytic molecules, as shown in the potential range of 0.3 to $0.35 \mathrm{~V}$ [19-21]. In the case of H-MAX with a lower oxygen content, the pseudo-capacitive current was negligible, while the rectangular shape of the CV curves was maintained, as shown in Fig. 6 (b). On the other hand, Ox-MAX with abundant oxygen functionalities showed a depressed rectangular shape compared to the other samples over the whole potential sweep range of $-0.27 \sim 0.69 \mathrm{~V}$, and the capacitance was much smaller than that of MAX or H-MAX (Fig. 6 (c)). In addition, the characteristic pseudo-capacitive current was observed at $0.3 \sim 0.35$ V. Fig. 6 (d) summarizes the specific capacitances of the Maxsorb III series derived from variable scan rates. Especially for Ox-MAX, the specific capacitances showed a rapid decrease when the scan rate was increased from 1 to $200 \mathrm{mV} / \mathrm{sec}$. These results suggest that the electrolyte ions do not easily diffuse within carbon micropores, where the surface is rich with surface functionalities.

Fig. 7 shows the Nyquist plots for the Maxsorb III series. The equivalent series resistances can be explained by summing the electronic and ionic contributions. The former is associated with an intrinsic electronic resistance of the carbon material itself and the interfacial resistances of carbon particles to carbon particles and carbon particles to the current collector. The latter refers to the ionic (diffusion) resistance of electrolyte ions moving through the electrolyte solution to the narrow pores [22-24]. As shown in Fig. 6, the electronic resistances for the model ACs were similar (around $2.9 \Omega$ ), indicating that the carbonaceous structures of the Maxsorb III series were essentially comparable, even after the $\mathrm{H}_{2}$ and $\mathrm{KOH}$ treatments. However, especially in the low-frequency region associated with the diffusion 
of electrolyte ions in the pores, the slope for Ox-MAX, with the highest oxygen contents, was gentle compared with those for MAX or H-MAX, indicating that the diffusion of the electrolyte ions was hindered in carbon micropores with abundant surface functionalities.

Based on the electrochemical results of the CVs and electrochemical impedance spectroscopy, it was concluded that the oxygen-containing surface functional groups on the surface of micropores interrupt the diffusion of electrolyte ions in the narrow pores. These results agreed with ethanol adsorption/desorption isotherm measurements and solid-state NMR analysis for the Maxsorb III series,

supporting our hypothesis, even though different adsorptive materials were used (ethanol and electrolyte ions in $\mathrm{H}_{2} \mathrm{SO}_{4}$ ).

\section{Conclusions}

In this report, $\mathrm{H}_{2}$ and $\mathrm{KOH}$ treatments were used to synthesize ACs with lower and higher contents of oxygen-containing surface functional groups and similar specific surface area and pore size, respectively. Abundant surface functionalities decreased the adsorption of ethanol and shortened the apparent adsorption equilibrium time. The solid-state NMR and electrochemical analyses confirmed that diffusional hindrance of ethanol molecules caused by surface functionalities in micropores of ACs decreases the adsorption amount and shortens the adsorption equilibrium time of ethanol.

\section{Acknowledgements}

The authors acknowledge financial support provided by the Japan Science and Technology AgencyCore Research for Evolutionary Science and Technology (JST-CREST) and the G-COE program (New Carbon Materials) of Kyushu University. This study was partially supported by the New Energy and Industrial Technology Development Organization (NEDO) under the Innovative Zero-emission Coalfired Power Generation Project. 


\section{References}

[1] I.I. El-Shrakawy, B.B. Saha, S. Koyama. J. He, K.C. Ng, C. Yap, Experimental investigation on activated carbon-ethanol pair for solar powered adsorption cooling application, Int. J. Refrig. 31 (2008) 1407-1413.

[2] P. A. Ostergaard, Wind power integration in Aalborg Municipality using compression heat pumps and geothermal absorption heat pumps, Energy 49 (2013) 502-508.

[3] K. C. Ng, H. T. Chua, C. Y. Chung, C. H. Loke, T. Kashiwagi, A. Akisawa, B.B. Saha, Experimental investigation of a silica gel-water adsorption characteristics, Appl. Therm. Eng. 21 (2001) 1631-1642.

[4] A. Chakraborty, B.B. Saha, S. Koyama, K.C. Ng, K. Srinivasan, Adsorption thermodynamics of silica gel-water systems, J. Chem, Eng. Data 54 (2009) 448-452.

[5] Y. Liu, K.C. Leong, The effect of operating conditions on the performance of zeolite/water adsorption cooling systems, Appl. Therm. Eng. 25 (2005) 1403-1418.

[6] B.B. Saha, S. Jribi, S. Koyama, I.I. El-Shrakawy, Carbon dioxide adsorption isotherms on activated carbons, J. Chem. Eng. Data. 56 (2011) 1974-1981.

[7] S. Shimooka, M. Yamazaki, T. Takewaki, E. Akashige, F. Ikehata, H. Kakiuchi, M. Kubota, H. Matsuda, Improvement of water adsorptivity of activated carbon for adsorption heat pump by hydrophilic treatment, ISETS07 (2007) 174-177.

[8] L.W. Wang, J.Y. Wu, R.Z. Wang, Y.X. Xu, S.G. Wang, Experimental study of a solidified activated carbon methanol adsorption ice maker, Appl. Therm. Eng. 23 (2003) 1453-1462.

[9] M. Lie, H.B. Haung, R.Z. Wang, L.L. Wang, W.D. Cai, W.M. Yang, Experimental study on adsorbent of activated carbon with refrigerant of methanol and ethanol for solar ice maker, Renew. Energ. 29 (2004) 2235-2244.

[10]H. Demir, M. Mobedi, S. Ulku, A review on adsorption heat pump: Problems and solutions, Renew. Sust. Energ. Rev. 12 (2008) 2381-2403.

[11]F. Watanabe, Y. Watabe, H. Katsuyama, J. Kozuka, M. Hasatani, Heat transfer accompanied by adsorption/desorption of water vapor in adsorption heat pump of packed bed type, Kagaku Kogaku Ronbunshu 19 (1993) 83-90 (in Japanese). 
[12]D. Attan, M.A. Alghoul, B.B. Saha, J. Assadeq, K. Sopian, The role of activated carbon fiber in adsorption cooling cycles, Renew. Sust. Energ. Rev 15 (2011) 1708-1721.

[13]T. Otowa, R. Tanibata, M. Itoh, Production and adsorption characteristics of MAXSORB: highsurface-area active carbon, Gas Sep. Purif. 4 (1993) 241-245.

[14] S.-I. Lee, K. Saito, K. Kanehashi, M. Hatakeyama, S. Mitani, S.-H. Yoon, Y. Korai, I. Mochida, ${ }^{11} \mathrm{~B}$ NMR study of the $\mathrm{BF}^{-4}$ anion in activated carbons at various stages of charge of EDLCs in organic electrolyte, Carbon 44 (2006) 2578-2586.

[15] K. Kaneko, C. Ishii, M. Ruike, H. Kuwabara, Origin of superhigh surface area and microcrystalline graphitic structures of activated carbons, Carbon 7 (1992) 1075-1088.

[16] N.H. Martin, J.D. Brown, K.H. Nance, H.F. Schaefer, III, P.v.R. Schleyer, Z.X. Wang, H.L. Woodcock, Analysis of the origin of through-space proton NMR deshielding by selected organic functional groups, Org. Lett. 24 (2001) 3823-3826.

[17] Y. Liang, Z. Li, X. Yang, R. Fu and D. Wu, Pore morphology: a vital factor in determining electrochemical properties of electrical double layer capacitors, Chem. Commun. 49 (2013) 999810000 .

[18] Y. Liang, F. Liang, H. Zhong, Z. Li, R. Fu and D. Wu, An advanced carbonaceous porous network for high-performance organic electrolyte supercapacitors, J. Mater. Chem. A 1 (2013) 7000-7005.

[19] T. Kim, S. Lim, K. Kwon, S.-H. Hong, W. Qiao, C.K. Rhee, S.-H. Yoon, I. Mochida, Electrochemical capacitances of well-defined carbon surfaces, Langmuir 22 (2006) 9086-9088.

[20] T. Kim, C. Ham, C.K. Rhee, S.-H. Yoon, M. Tsuji, I. Mochida, Morphological reason for enhancement of electrochemical double layer capacitances of various acetylene blacks by electrochemical polarization, Electrochim. Acta, 53 (2008) 5789-5795.

[21] T. Kim, C. Ham, C.K. Rhee, S.-H. Yoon, M. Tsuji, I. Mochida, Effects of oxidation and heat treatment of acetylene blacks on their electrochemical double layer capacitances, Carbon 47 (2009) 226-233.

[22] A.G. Pandolfo, A.F. Hollenkamp, Carbon properties and their role in supercapacitors, J. Power Sources 157 (2006) 11-27.

[23] Q.T. Qu, B. Wang, L.C. Yang, Y. Shi, S. Tian, Y.P. Wu, Study on electrochemical performance of activated carbon in aqueous $\mathrm{Li}_{2} \mathrm{SO}_{4}, \mathrm{Na}_{2} \mathrm{SO}_{4}$ and $\mathrm{K}_{2} \mathrm{SO}_{4}$ electrolytes, Electrochem. Commun. 10 (2008) 1652-1655. 
[24] Z.B. Wen, Q.T. Qu, Q. Gao, X.W. Zheng, Z.H. Hu, Y.P. Wu, Y.F. Liu, X.J. Wang, An activated carbon with high capacitance from carbonization of a resorcinol-formaldehyde resin, Electrochem. Commun. 11 (2009) 715-718. 
Table 1. Pore structural parameters and elemental compositions of the Maxsorb III series.

\begin{tabular}{|c|c|c|c|c|c|c|c|c|}
\hline \multirow[b]{2}{*}{ Sample } & \multicolumn{4}{|c|}{ Pore structural parameters } & \multicolumn{4}{|c|}{ Elemental compositions (wt.\%) } \\
\hline & $\begin{array}{c}\text { Total } \\
\text { surface } \\
\text { area } \\
\left(\mathrm{m}^{2} \mathrm{~g}^{-1}\right)\end{array}$ & $\begin{array}{c}\text { External } \\
\text { surface } \\
\text { area } \\
\left(\mathrm{m}^{2} \mathrm{~g}^{-1}\right)\end{array}$ & $\begin{array}{c}\text { Micropore } \\
\text { volume } \\
\left(\mathrm{cm}^{3} \mathrm{~g}^{-1}\right)\end{array}$ & $\begin{array}{c}\text { Average } \\
\text { pore width } \\
(\mathrm{nm})\end{array}$ & $\mathrm{C}$ & $\mathrm{H}$ & $\mathrm{N}$ & $\mathrm{O}_{\text {diff. }}$ \\
\hline MAX & 3,045 & 14.2 & 1.70 & 1.12 & 95.13 & 0.14 & 0.25 & 4.35 \\
\hline H-MAX & 3,029 & 19.3 & 1.73 & 1.15 & 97.91 & 0.22 & 0.12 & 1.75 \\
\hline Ox-MAX & 2,992 & 22.3 & 1.65 & 1.11 & 89.15 & 0.27 & 0.08 & 10.46 \\
\hline
\end{tabular}




\section{Figure Captions}

Fig. 1. Schematic diagram of the gravimetric adsorption apparatus.

1. Pressure gauge, 2. Liquid ethanol vessel, 3. Adsorption chamber, 4. Quartz spring, 5. Sample basket, 6. Diffusion and rotary pumps, 7. Isothermal water bath, 8. Isothermal air bath.

Fig. 2. (a) $\mathrm{N}_{2}$ adsorption/desorption isotherms and (b) isotherms on a log scale for the Maxsorb III series at $77 \mathrm{~K}$.

Fig. 3. (a) Ethanol adsorption/desorption isotherms and (b) adsorption/desorption equilibrium times of the Maxsorb III series at $303 \mathrm{~K}$.

Fig. 4. ${ }^{2} \mathrm{H}-\mathrm{NMR}$ spectra of the $\mathrm{CD}_{3} \mathrm{CH}_{2} \mathrm{OH}$-adsorbed Maxsorb III series.

Fig. 5. ${ }^{2} \mathrm{H}-\mathrm{NMR}$ spectra of the $\mathrm{CH}_{3} \mathrm{CH}_{2} \mathrm{OD}$-adsorbed Maxsorb III series for a (a) narrow chemical shift range and (b) wide chemical shift range.

Fig. 6. Cyclic voltammograms of (a) MAX, (b) H-MAX, and (c) Ox-MAX measured at different scan rates in $\mathrm{H}_{2} \mathrm{SO}_{4}$. The specific capacitances for each scan rate were summarized in graph (d).

Fig. 7. Nyquist plots for the Maxsorb III series. 
The English in this document has been checked by at least two professional editors, both native speakers of English. For a certificate, please see:

http://www.textcheck.com/certificate/fQ0dgB 


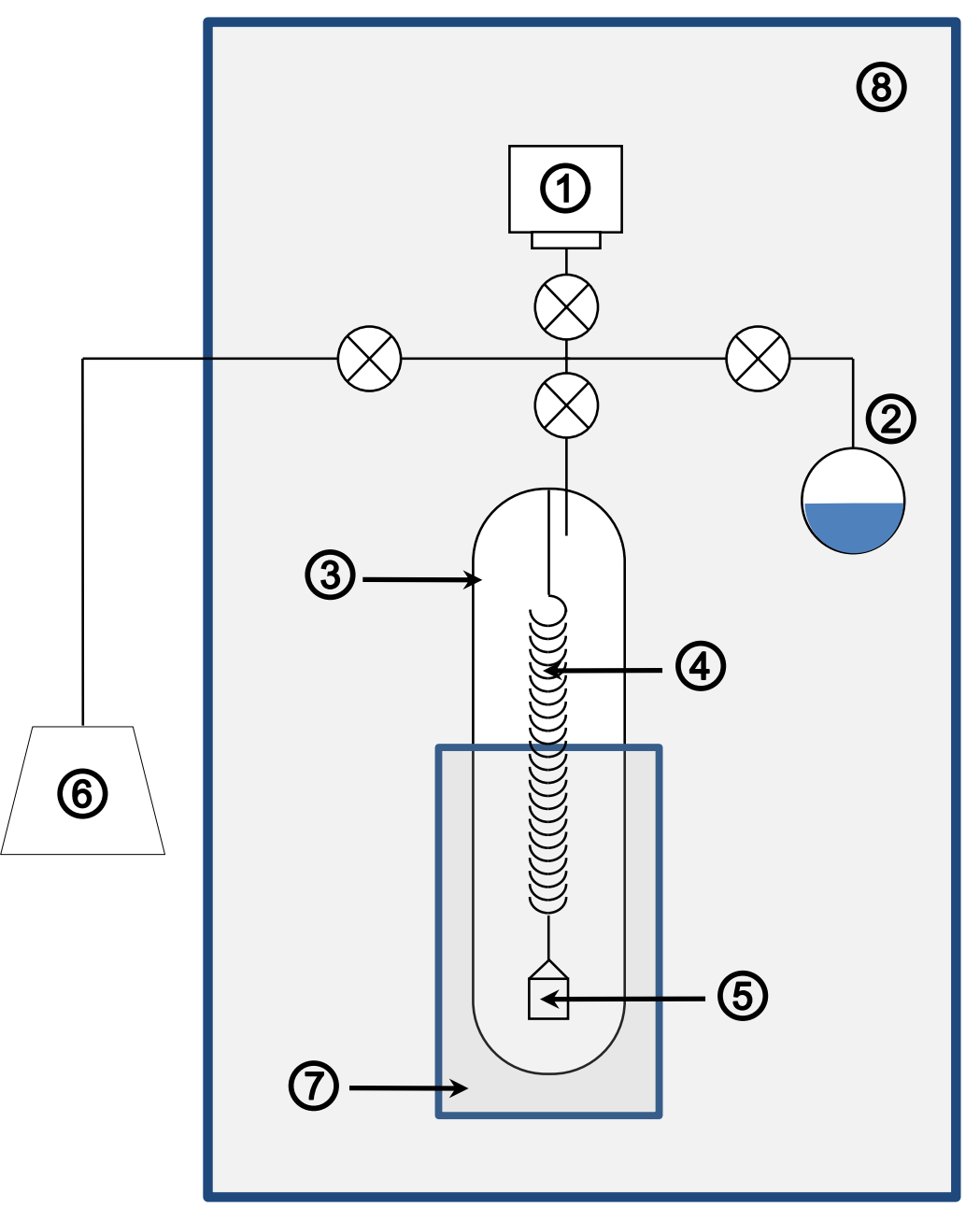

Fig. 1. 

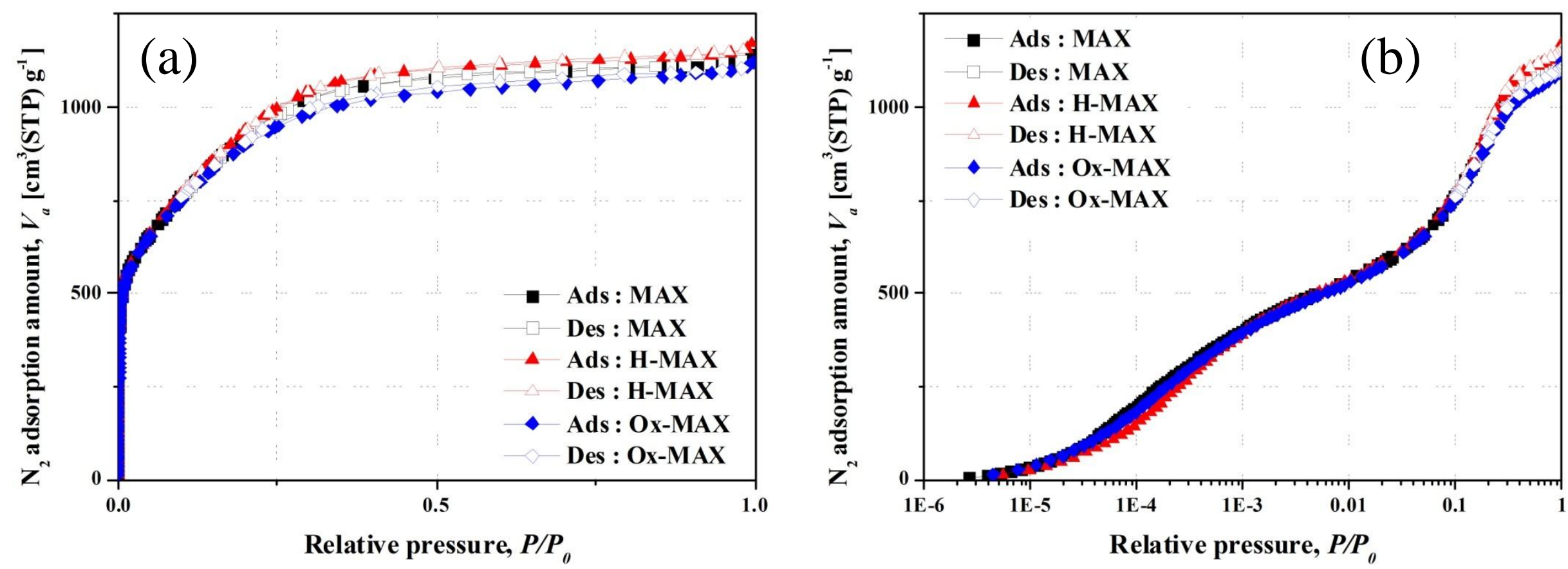

Fig. 2. 

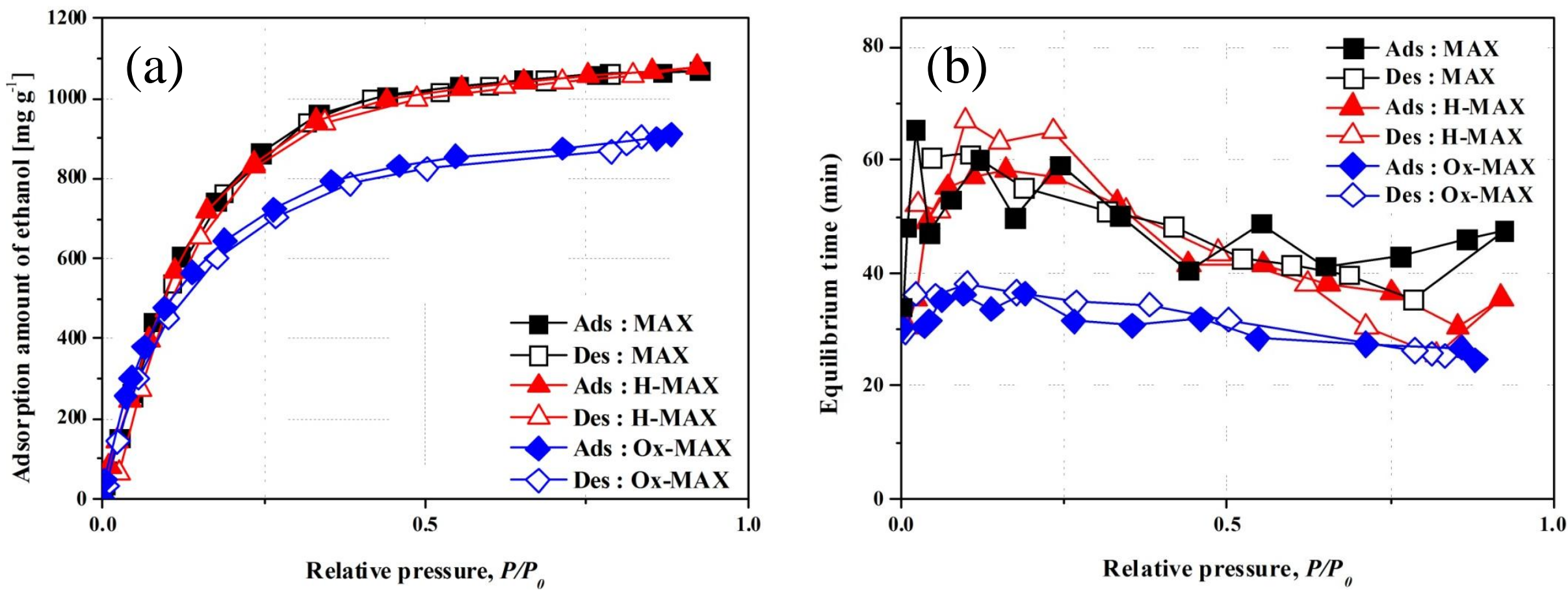

Fig. 3. 


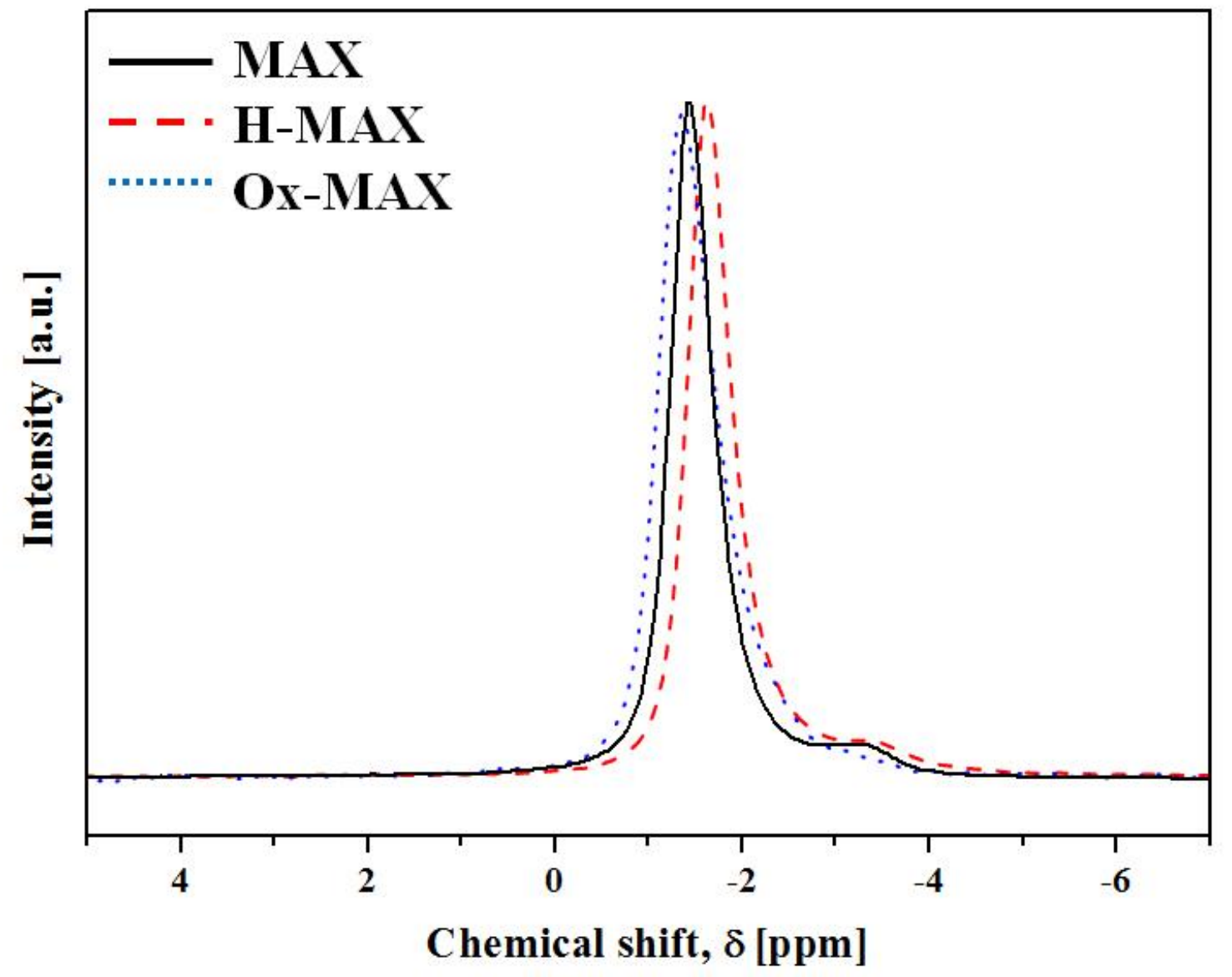

Fig. 4. 

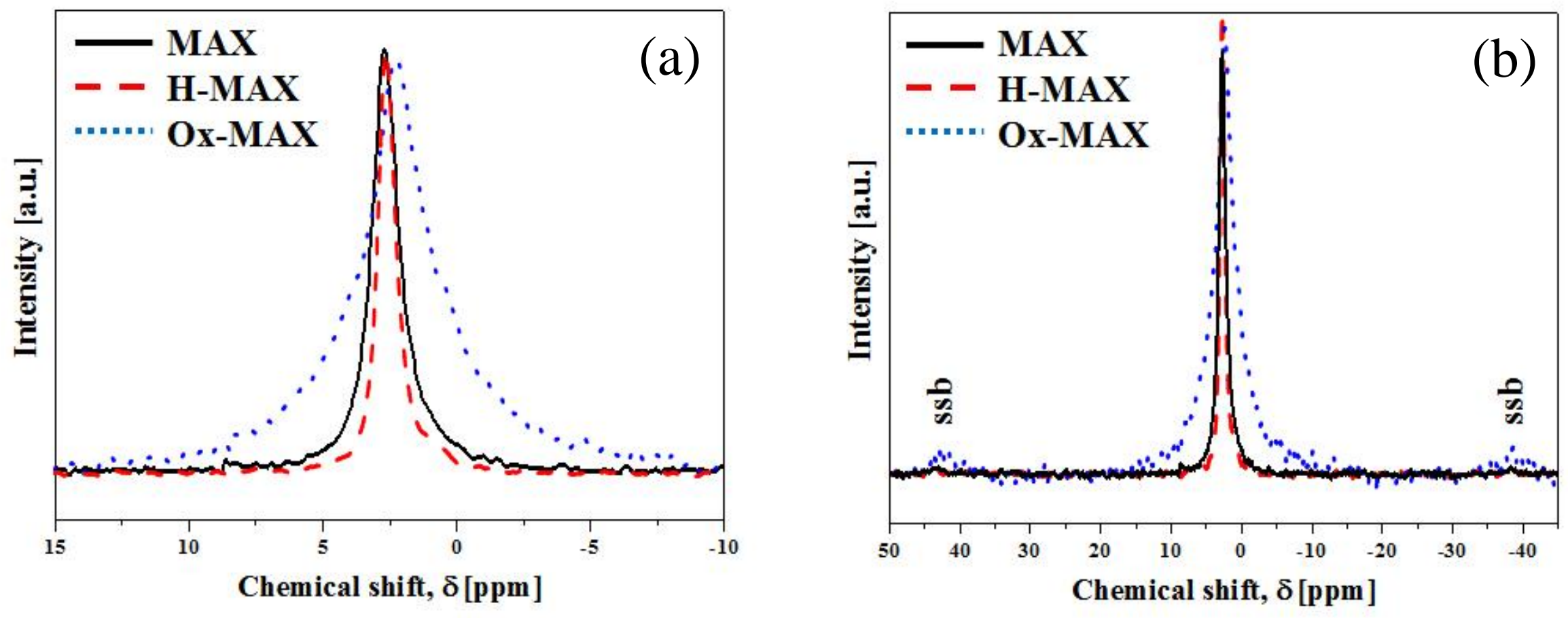

Fig. 5. 


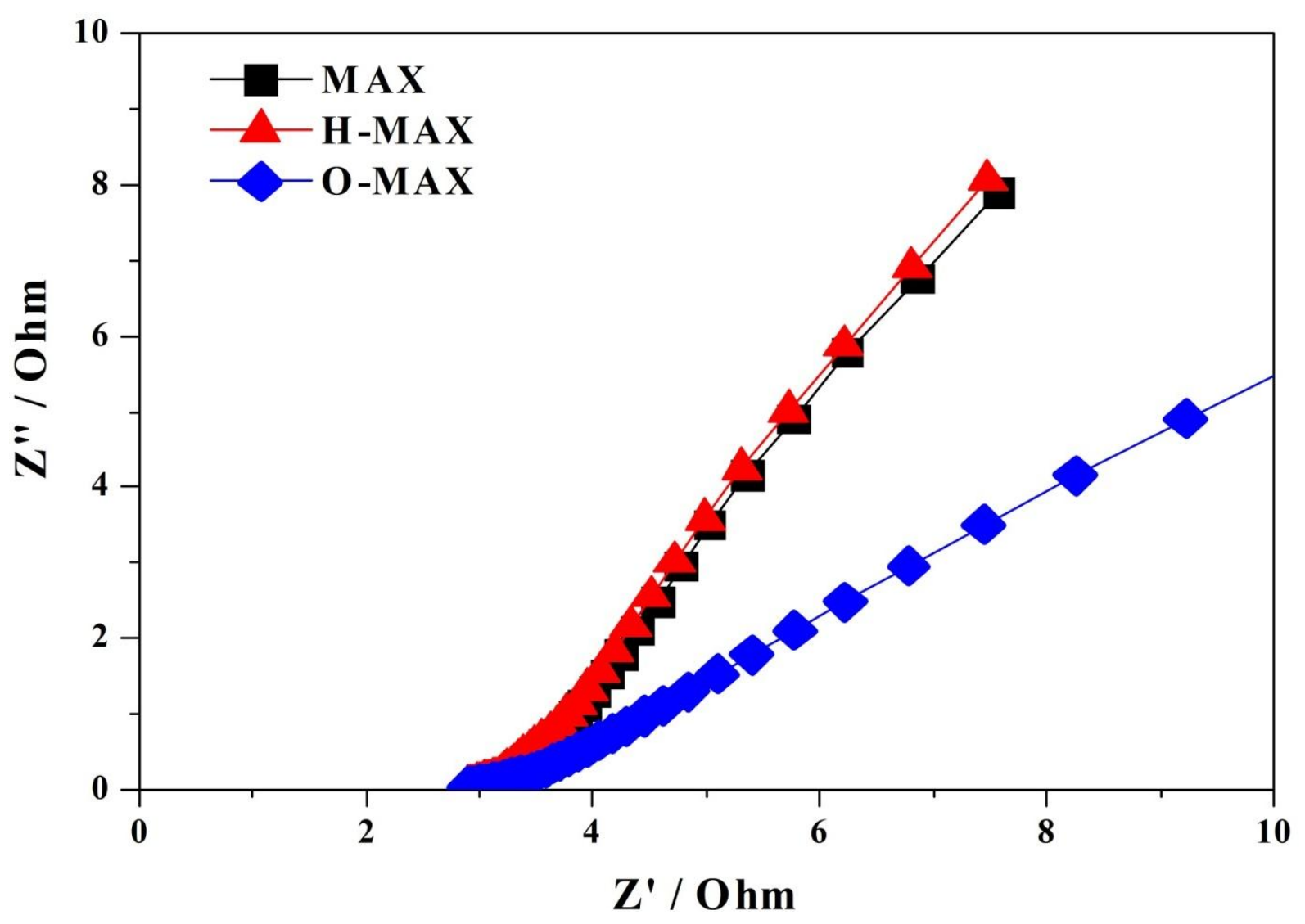

Fig. 7. 


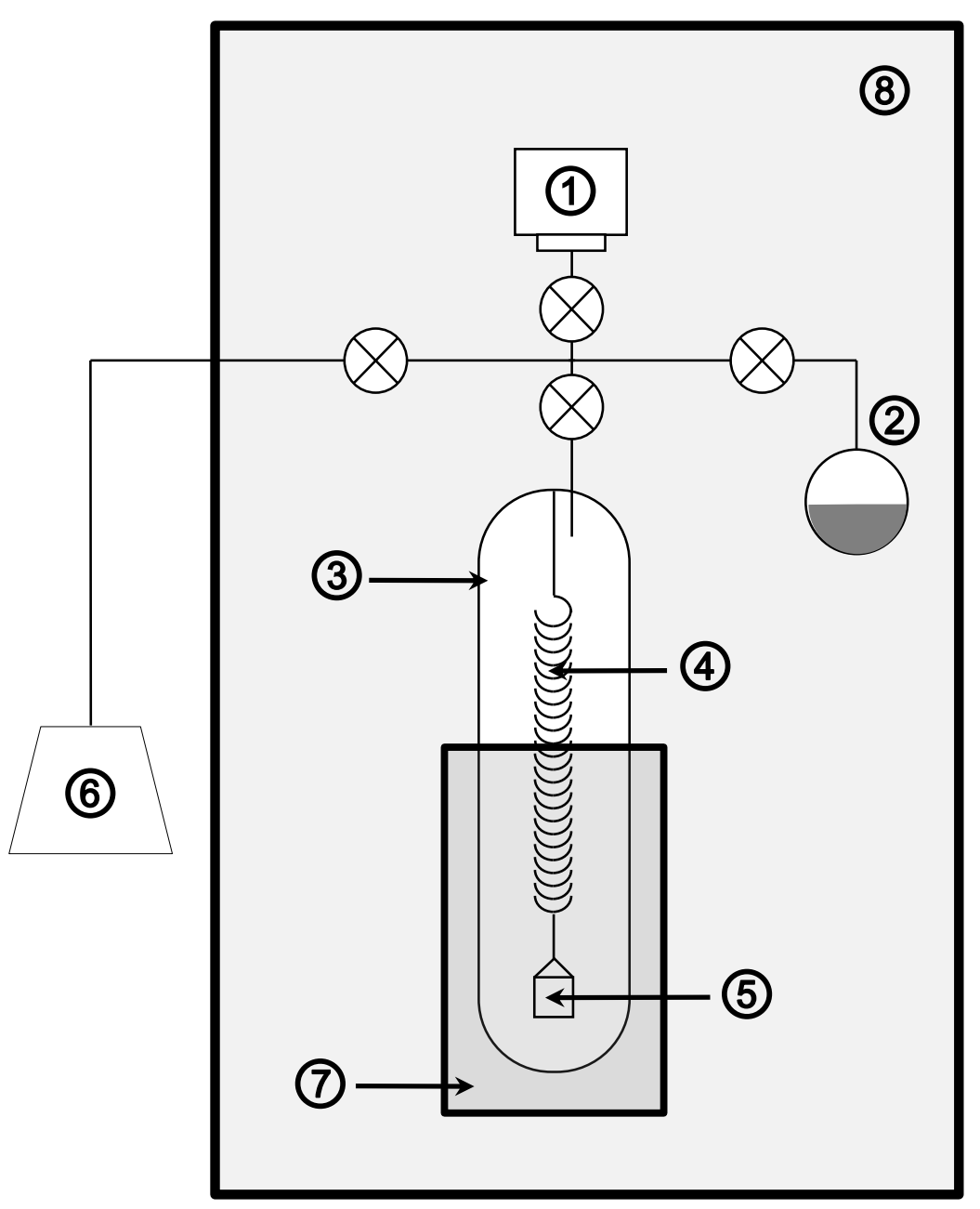

Fig. 1. 

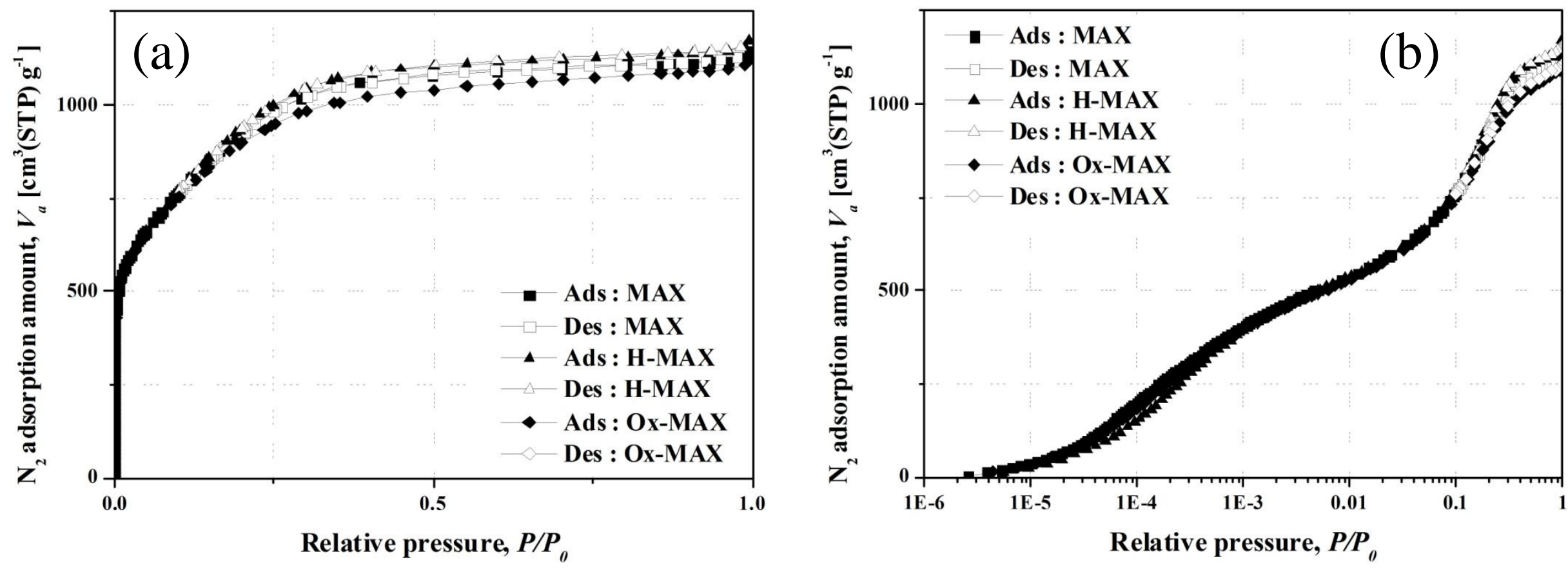

Fig. 2. 

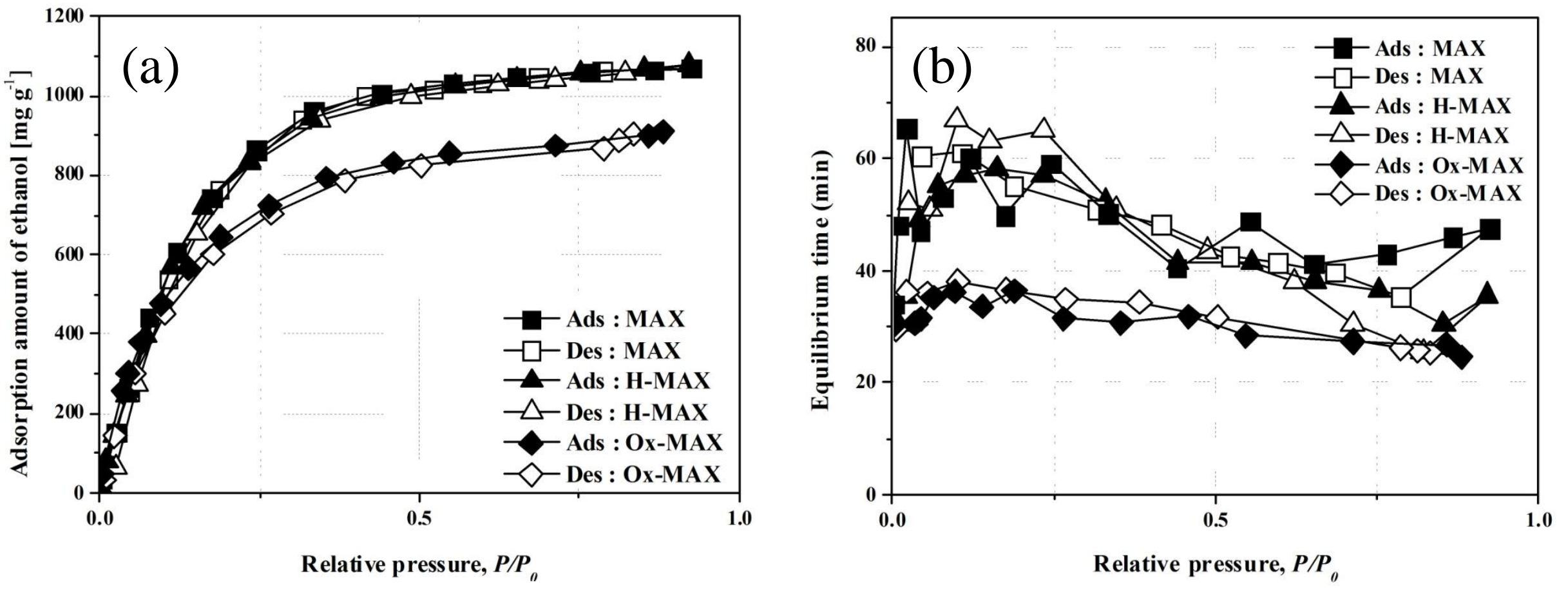

Fig. 3. 


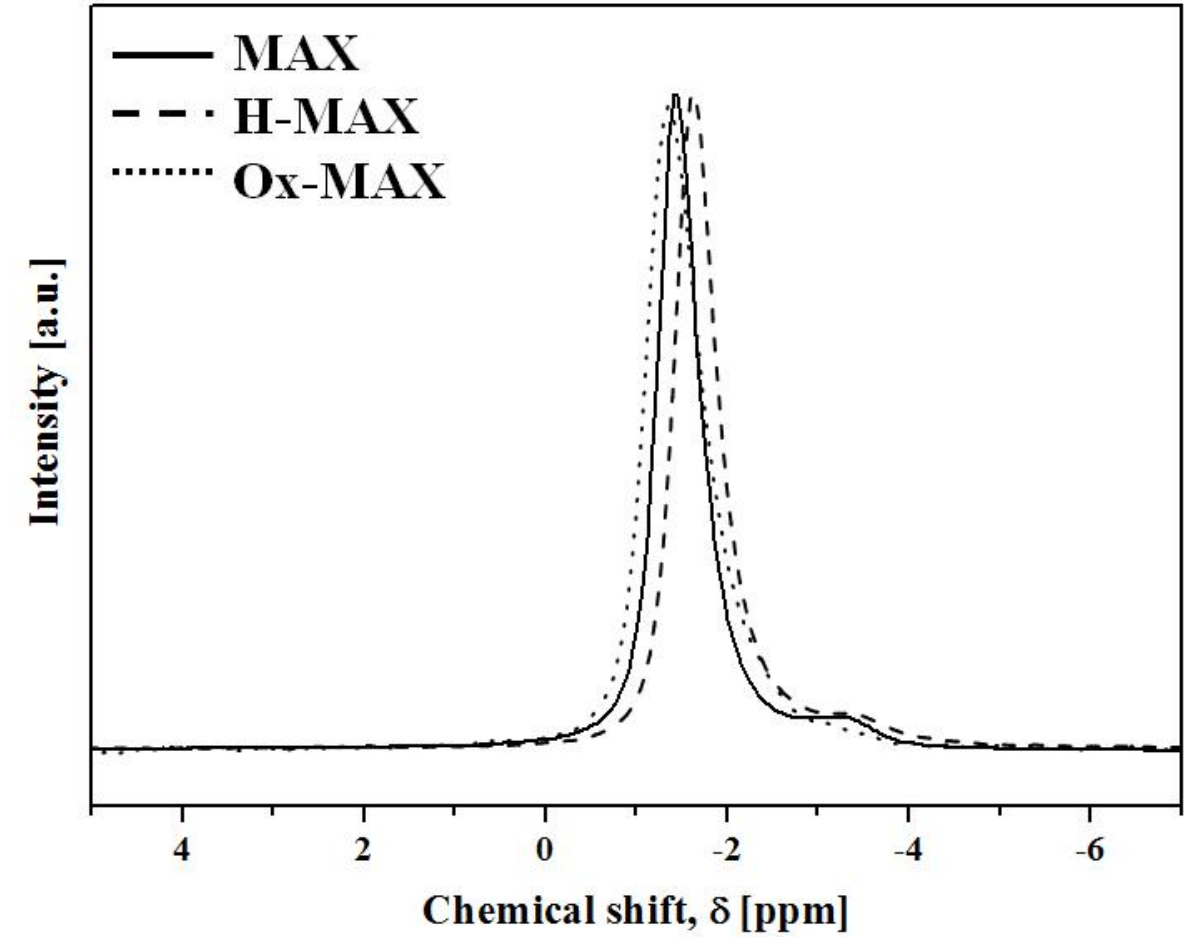

Fig. 4. 

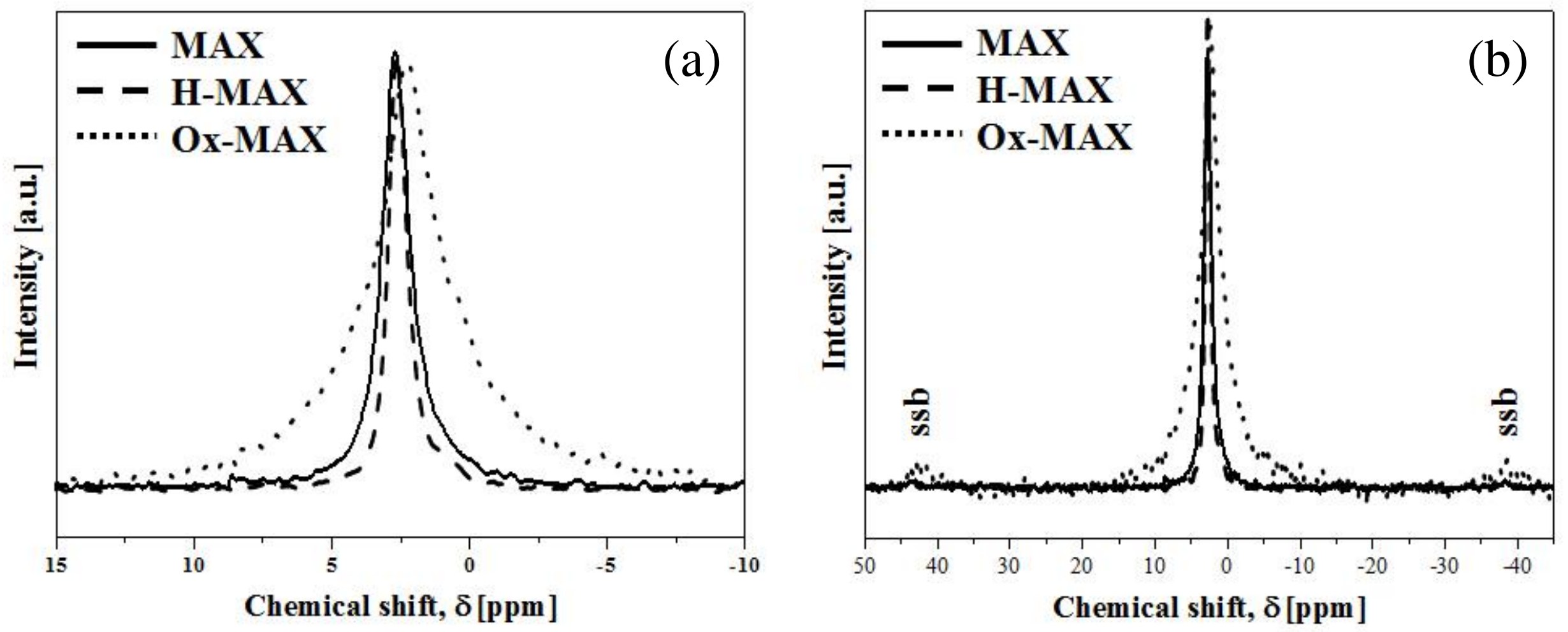

Fig. 5. 

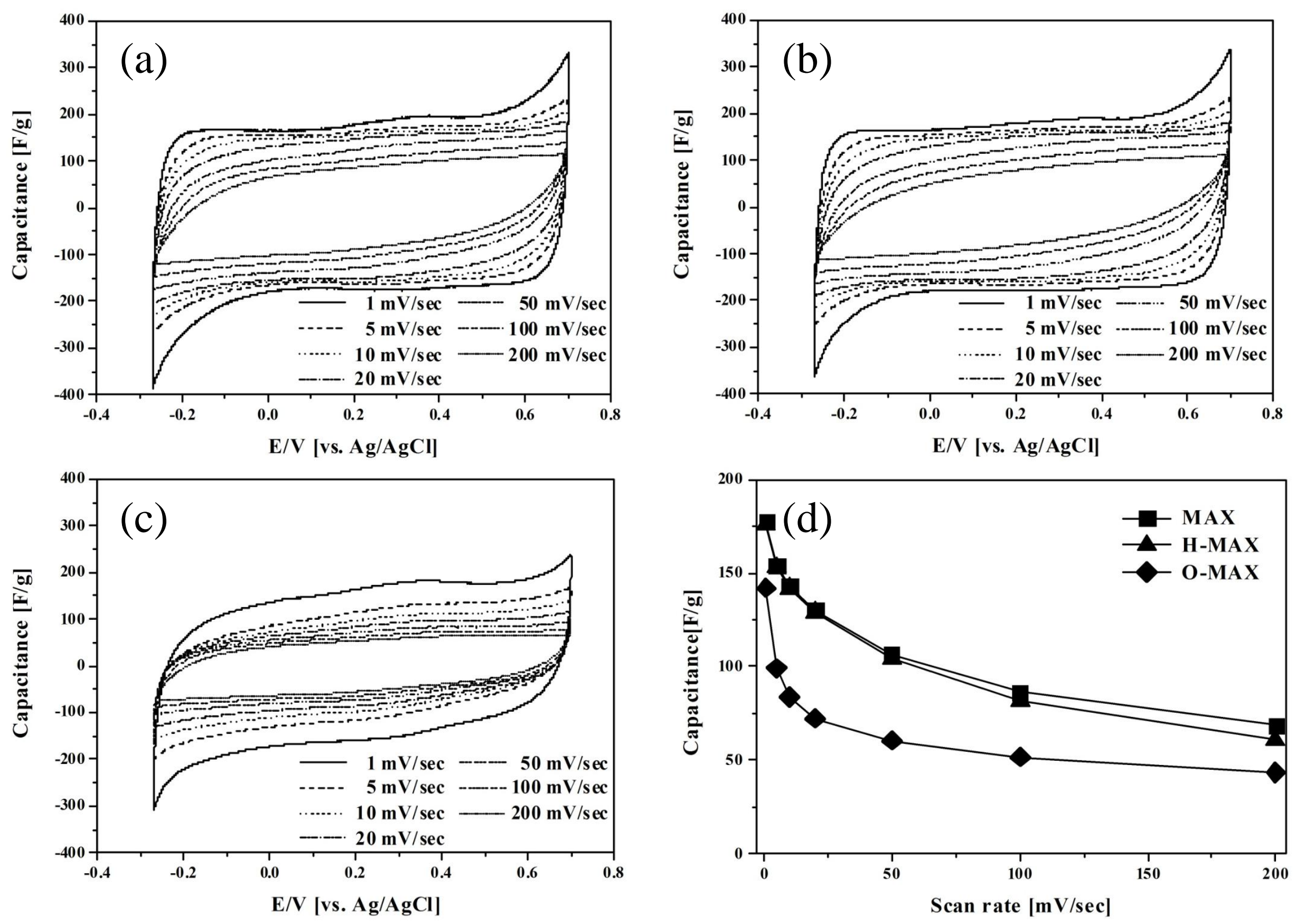

Fig. 6. 


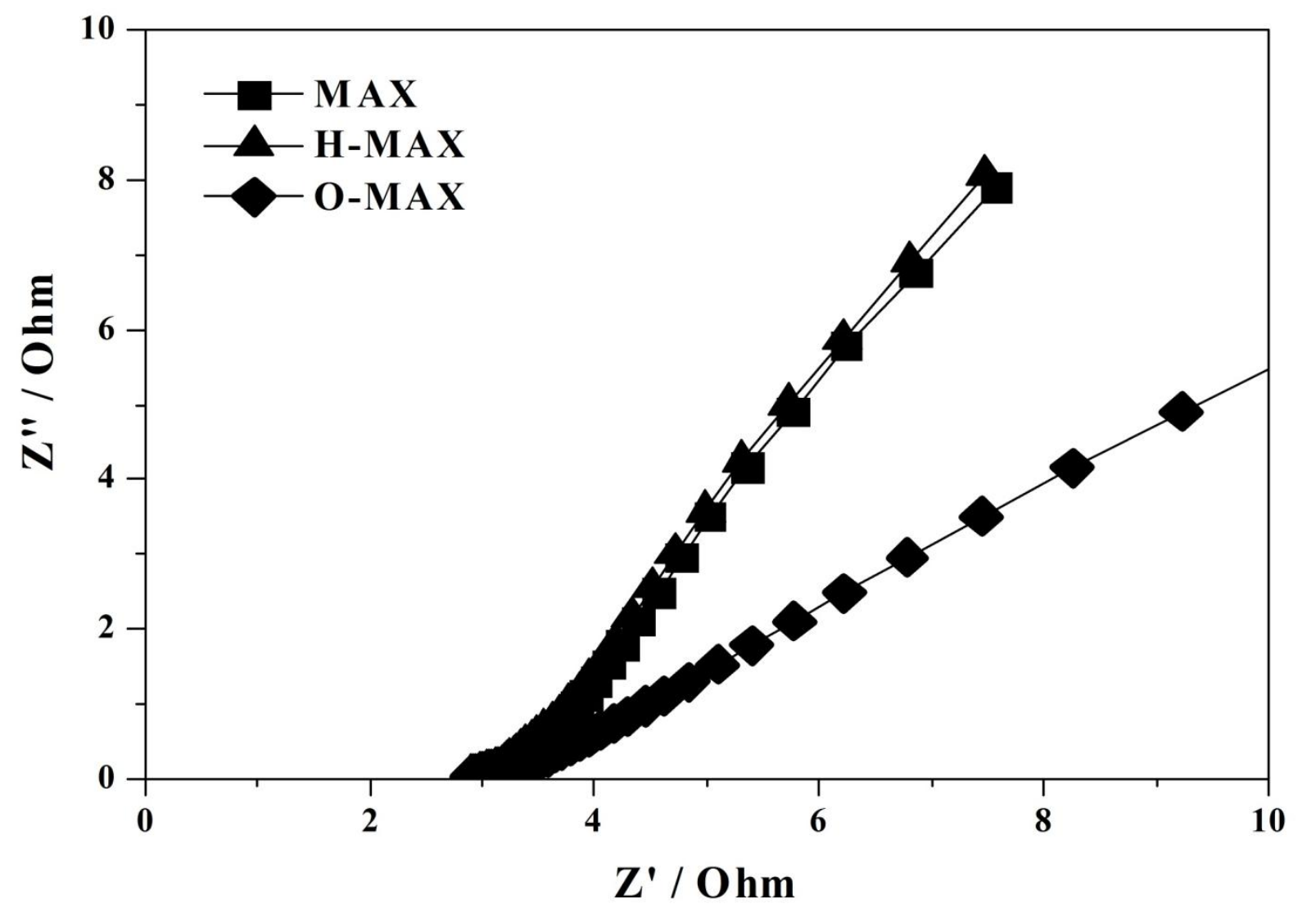

Fig. 7. 


\section{Graphitic abstract}

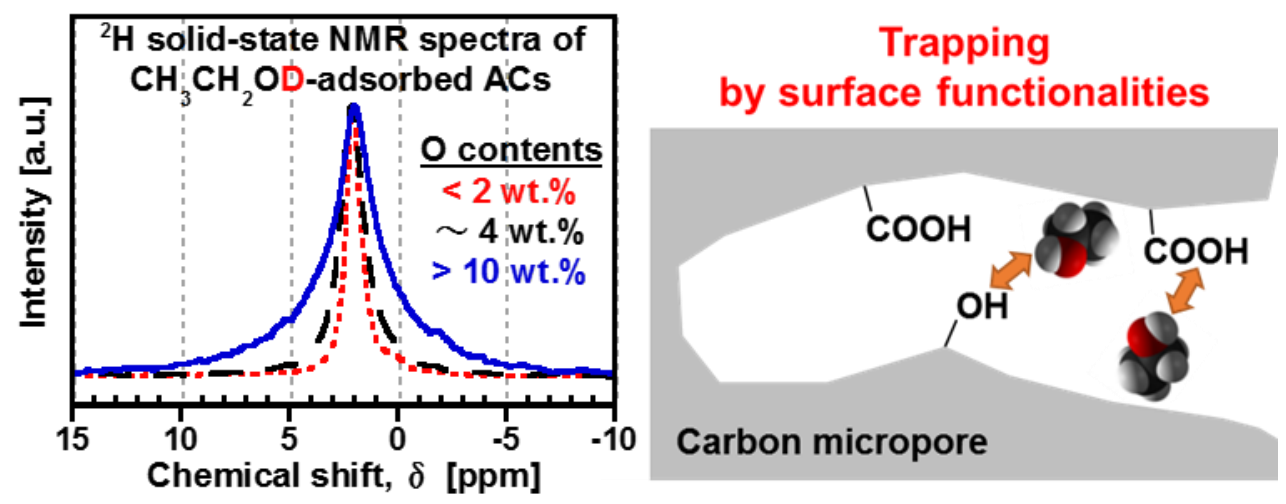

